POLITECNICO DI MILANO - Dipartimento di Architettura e Pianificazione Laboratorio di Analisi e Diagnostica del Costruito

via Garofano, 39 - 20133 Milano

Tel. +39 (0)2.23.99.94.47 - Fax. +39 (0)2.23.99.94.45 - email davide.delcurto@polimi.it

\title{
THERMO - HYGROMETRICAL SURVEYINGS and MICROCLIMATE MONITORING at the SAN BENEDETTO PO ABBEY (Mantova - Italy)
}

Authors: Davide Del Curto, Alberto Grimoldi

Politecnico di Milano - DIAP, Via Garofano 39 - 20133 Milano, Italy

Keywords: passive procedures, moisture, historical architecture, masonry texture, microclimate monitoring

The aim of this research is to develop IRT procedures for the monitoring of thermo - hygrometrical conditions of ancient buildings and surveillance of risk areas.

The greater part of degradation phenomena such as decay of plasters and frescoes, damaging of stone and wood elements, actually can be led back to moisture. Water acts both as enviromental humidity determining microclimate $(\mathrm{RH}-\mathrm{SH})$, both by bathing mansonry moreover as of capillarity. The campaign of surveyings lead on San Benedetto Po abbey (Mantova) has been extended for 3 years with the aim to inquire the exchange dynamics between microclimate and masonry; surveyings have regarded thermo - hydrometrical data $\mathrm{T}, \mathrm{RH}, \mathrm{SH}$, collected both for microclimate (internal enviroments), both for masonry. ${ }^{1}$

Particularly IRT has been employed to map thermal gradient on the masonry surfaces and has integrated in innovative way with the psycrometrical reliefs and quantitative tests of water content in masonry.

The localisation of the thermal gradients, particularly in colder areas on masonry surfaces where condensation may occour, is an important issue for early detection of damage.

IRT tests can be periodically repeated in passive way with low cost and without any damage for the wall; repetition of the test allows to find out variations of superficial temperature which is due to any unbalance between masonry and microclimate; it also constitutes an early alert for damages that will occur in case microclimate conditions do not change.

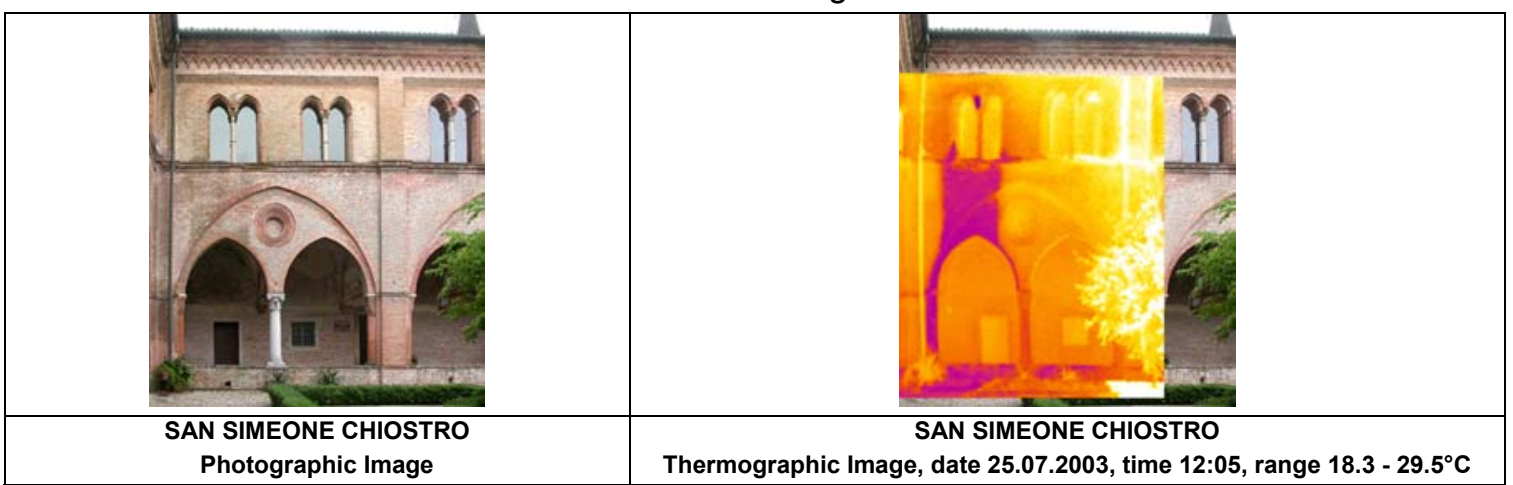

The evolutionary character of the processes of decay connected to moisture has determined the necessity to set up a long time program of surveyings in order to acquire data in the most various external conditions and to return them as a trend. To such aim 4 strucks have been carried out to intervals of 4 and 7 months, at the beginning and at the end of the warm season.

In order to the remarkable extension of San Benedetto abbey, the monitoring of the thermo hygrometrical conditions of the masonry has been preceded from a program of preliminary surveyings in the parts of the abbey where the degradation was manifest and in the zones whose

\footnotetext{
1 The campaing has been started by the Laboratorio di Analisi e Diagnostica del Costruito, Politecnico di Milano, in 2003. A. Grimoldi and E. Rosina.
} 
constructive history could suggest the presence of meaningful alterations in the structural order and, above all, in the collection system and removal of meteoric waters.

During this phase of pre - diagnosis IRT has been placed side by side to traditional techniques of stratigraphical analysis and has supplied an important support in order to read the masonry texture under plaster and to map the surfaces interested by moisture and capillarity; particularly it has allowed to reduce the number of samplings (drilling tests) for the determination of the water content in the masonry by means of quantitative tests.

Like described for masonries, also for monitoring the enviromental microclimate, the diagnosis has been articulated on two levels of sharpening: first a thermo - hygrometrical monitoring of the enviromental microclimate has been made by means of fixed probes for every day recording (to hour interval) of $T^{\circ}$ and U.R. \% in every parts of the Abbey; then a campaign of psychrometrical surveys has been carried out in the most valuable rooms and in zones with critical microclimatic conditions.

The psychrometrical relief consists in a series of thermo-hygrometrical surveys executed according to an orthogonal mesh and overlapped to the plan of every room; collected data concur to draw maps able to evaluate very easy the distribution of ITI, HR, SH, diagnosis of the imbalances (and their causes), dangerous both for historical surfaces of ancient buildings both for the objects conserved to their inside.

\section{RESULTS}

The results obtained from this surveyings denounce the presence of an increasing hygrometrical gradient from the inside to the outside of masonry and from the bottom to the high. Water content diagrams allow to put in evidence that the part where moisture level reaches dangerous concentrations for the conservation of the building does not exceed $70 \mathrm{~cm}$ height from the ground. Comparative reading of data moreover has allowed to design some synthetic maps concerning the distribution of enviromental humidity and to identify areas with the higher probability of risk for structures.

The present resesarch has also permitted to develop IRT, as an important support for reading of the masonry texture under plaster, for stratigraphical analysis and, finally, for a complete historical description of an ancient building carried on with the method of the Raumbuch.

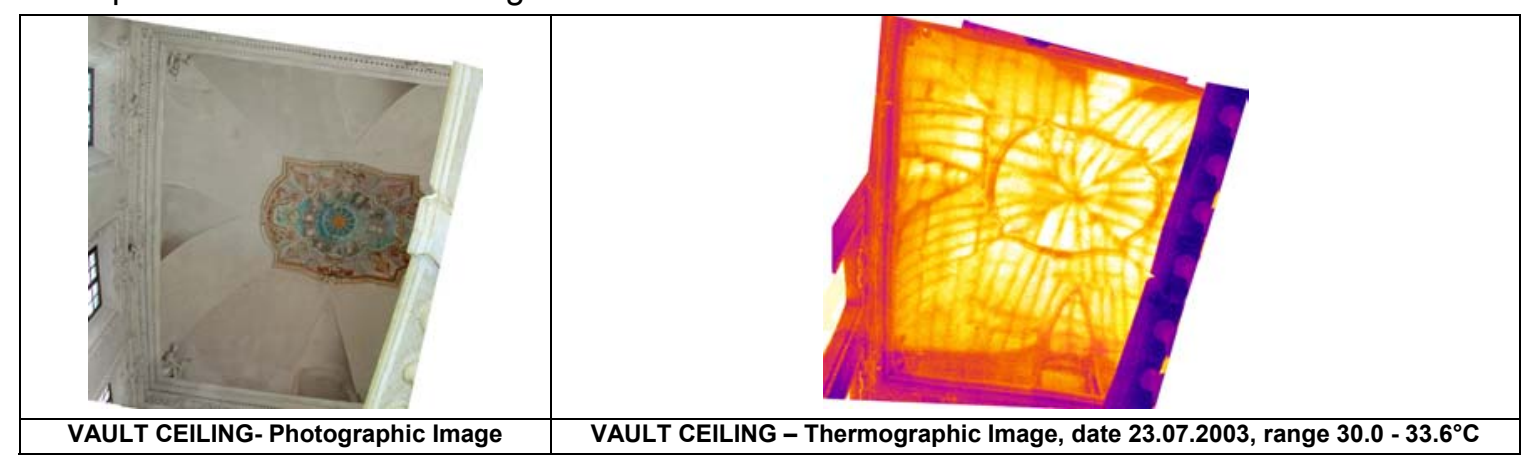

\section{FURTHER RESEARCHES}

The research has allowed to develop the potentialities of IRT in order to search and map the differences of temperature in the masonry and his connection with the other system in order to find, measure and control enviromental conditions of temperature and humidity.

The research will continue by monitoring microclimate during the start up of the new system of heating and air conditioning whose planning will be supported from the reliefs already made till today. 